\title{
MULTIPLE SPIKE STALL CELLS IN LOW SPEED AXIAL COMPRESSOR ROTOR BLADE ROW
}

\author{
Reza Taghavi-Zenouz \\ School of Mechanical Engineering, Iran University of Science and Technology, Tehran, Iran \\ e-mail: taghavi@iust.ac.ir \\ SARALlAH ABBASI \\ School of Mechanical Engineering, Arak University of Technology, Arak, Iran \\ e-mail:s_abbasi@iust.ac.ir
}

\begin{abstract}
Inception and development of multiple stall cells of short length scales are numerically investigated in an axial compressor rotor blade row. The method of investigation is based on time accurate three-dimensional full annulus simulations. Time dependent flow structure results revealed that there are two criteria responsible for inception of a special kind of stall, introduced as spike stall in the literature. These criteria are defined as leading edge spillage and trailing edge backflow, which occur at specific mass flow rates near to stall conditions. The numerical results revealed that once the spike stall cells appear, they cover roughly two blade passages in the circumferential direction and cover about $25 \%$ of the blade height. By further revolution of the blade row, the number of cells tends to increase. For the present case study, the number of stall cells increased to three after 8.5 rotor revolutions from the moment of the initial spike stall occurrence. Even at this moment, both of the above mentioned criteria for the spike stall inception have been observed within the blades passages. These events caused the inlet relative flow angle to the blade rows, and therefore the flow incidence angle and consequent blockage to the main flow, to increase. The tip leakage flow frequency spectrum has been studied through surveying instantaneous static pressure signals imposed on pressure side of the blades and also on the casing walls. These latter results showed that any further revolving of the rotor blade row, exceeding 8.5 revolutions, causes the spike stall to disturb the flow structure significantly.
\end{abstract}

Keywords: axial compressor, spike stall inception, tip leakage flow, frequency spectrum

\section{Introduction}

Rotating stall is known as one of the critical unsteady flow phenomena in dynamic compressors. This phenomenon, as a result of separation of flow from the blade surfaces, moves along the blade row in the circumferential direction. These separated circulatory flows, known as the stall cells, can produce blockages to the main flow within the blade passages. The rotating stall also changes pressure distributions on the blade surfaces in a periodic manner. Therefore, it would be responsible for noise generation and excitation of blade vibrations in different modes. The consequent unsteady forces may cause the compressor blades to be subjected to fatigue and fracture phenomena.

So far, rotating stall inception and the consequent unsteady flow structure in axial compressors have been of the interests of many researchers. It has been one of the most challenging topics in the history of gas turbines. Two types of rotating disturbances, accompanied by the stall inception in axial compressors are recognized and introduced as "modal" and "spike" modes (Day, 1993; Garnier et al., 1991). These stall precursors in low and high-speed axial compressors 
have been extensively and continuously studied since the early 1990s. Results of these investigations have been used by designers for a proper control of flow instabilities within the axial compressors.

The modal mode, generally referred to as "modal wave" or "long-wave length" inception, has been predicted by the compression system stability model of Moore and Greitzer (1986). This unsteady mode has been observed and reported by some researchers in various compressors (Day, 1993; Garnier et al., 1991). These disturbances rotate within the compressor annulus in the direction of the rotor rotation (when viewed from the stationary frame of reference). Many studies have shown that the modal stall can be described with no need to examination of flow details within the passage. The model introduced by Moore and Greitzer (1986) offers useful information about the commencement of flow instabilities such as rotating stalls and surge. Spakovszky (2001) also presented some information about the flow stability of different modes in axial compressors. However, the main shortcome of the most models, which have been presented so far, is their failure in reliable prediction of the surge line. In fact, single/two dimensions models which are presented by these researchers are not able to provide accurate information of these inherent complex three-dimensional flow instabilities.

Axial compressors may exhibit a short length-scale stall (i.e., spike stall) inception. This phenomenon, which is less understood so far, was first described by Day (1993). It is characterized by appearance of a disturbance or "spike" with two to three blade pitches width at the rotor blades tip. Along with the advances of the computational fluid dynamics techniques, some recent numerical investigations reveal the causal links between the blade tip clearance features and the onset of the rotating stall. Hoying et al. (1999) suggested that the spike type of the rotating disturbance might be explained by the behavior of the tip leakage vortex moving upstream the rotor blades row as the incidence angle increases. Hah et al. (2004) explained the relation between the tip leakage vortex and the rotating disturbance via unsteady three-dimensional numerical simulation for a low speed axial compressor. Vo et al. (2008) confirmed that the presence of transient tip clearance backflow at the trailing edge and spillage of the leading edge flow in the tip region are two criteria for the spike stall inception. Afterward, Deppe et al. (2008) surveyed the criteria introduced by Vo et al. (2008) through their experimental studies and obtained good consistency.

Other unsteady flow phenomena have also been recognized at the near-stall conditions through experimental and numerical investigations by some researchers. One type of the tip leakage flow unsteadiness in axial compressors was reported by Mailich et al. (2001) as rotating instability. They realized that at some specified operating conditions the tip leakage vortex moves from one blade to another. This phenomenon has been studied in both the low and high speed compressors. Marz et al. (2001) ascribed this phenomenon to existence of the induced vortex which rotates at about 50\% blade passing frequency. Hah et al. (2006) surveyed the occurrence of this phenomenon at high speed compressors experimentally and numerically, respectively. They showed that this unsteadiness originates from interaction of the induced vortex flow and shock wave formed at the blade leading edge. They concluded that the breakdown of the tip leakage vortex occurs at the near-stall condition, and not only it results in unsteadiness, but also produces a large reversed flow and blockage in the rotor tip region. Furukawa et al. (1999, 2000) numerically presented consequences of the tip leakage vortex breakdown which result in unsteadiness in axial compressors.

Although the above-mentioned unsteady flow phenomena are related to the blade tip leakage vortex, details of the flow field especially the process of inception and development of the spike stall cells are still under question. In the present research work, development of multiple spike stall cells with short-length-scale is investigated in an axial compressor rotor blade row, based on the full annulus numerical simulation. 


\section{Model specifications and numerical procedure}

The model used in the present investigation is a low speed isolated axial compressor rotor blades row. This rotor has been also the subject of investigations of other researchers from either experimental or numerical point of views (Inoue et al., 1986; Furukawa et al., 1999). The proposed rotor blade row is comprised of 12 blades of NACA-65 airfoil series type. Geometric specifications of this rotor blade row are summarized as in Table 1 (Inoue et al., 1986). The rotational speed of the rotor blade row and the blade tip clearance size is $1300 \mathrm{rpm}$ and $2 \mathrm{~mm}$, respectively.

Table 1. Geometric specifications of the model

\begin{tabular}{|c|c|c|c|c|}
\hline $\begin{array}{c}\text { Outer } \\
\text { diameter [mm] }\end{array}$ & $\begin{array}{c}\text { Hub to tip } \\
\text { ratio }\end{array}$ & $\begin{array}{c}\text { Tip clearance } \\
\text { [\% of chord] }\end{array}$ & $\begin{array}{c}\text { Tip chord } \\
\text { length [mm] }\end{array}$ & $\begin{array}{c}\text { Solidity of rotor } \\
\text { blades at tip }\end{array}$ \\
\hline \hline 449 & 0.6 & 1.7 & 117.5 & 1 \\
\hline
\end{tabular}

For a precise flow simulation and more accurate description of the unsteady flow structure the whole annulus including all the blades, as shown in Fig. 1, has been modeled. A multi-block structured grid system has been employed for the numerical calculations. The surface mesh system, generated on the model solid walls, is shown in the above figure. Each flow passage includes 74 streamwise, 50 spanwise and 60 pichwise nodes. The mesh structure should be of suitable density distribution especially in the blade tip clearance region and near to solid walls to be able to resolve the flow characteristics precisely. The radial space between the blade tip and the compressor casing is divided into 16 nodes. The mesh density near the walls ensured that the $y^{+}$values to be kept at less than 5, enabling the viscous sub-layer to be resolved, precisely. The whole grid system consisted of about 2700000 cells. Mesh independency studies have been performed for confidence of the right results. No significant variations in the results have been observed by increasing the number of meshes exceeding that considered through the final calculations.

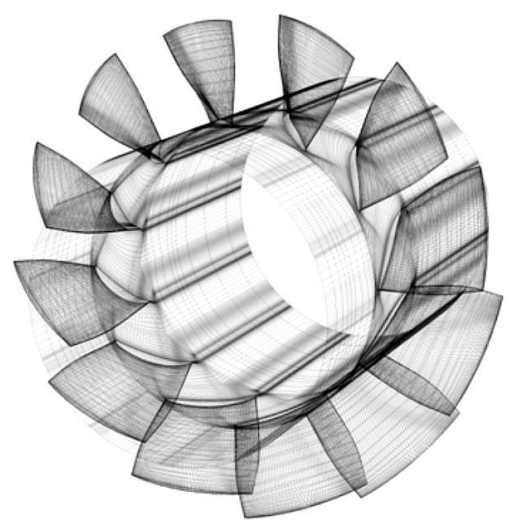

Fig. 1. Computational geometry and surface grid distribution

The well-known commercial flow solver of FLUENT is used for the current study. This adopted solver is a three-dimensional, viscous, time accurate code which utilizes a finite volume scheme for solution of the governing equations of continuity and momentum. The upwind second-order discretization scheme has been used to reduce the effect of numerical diffusion on the solution. To solve the unsteady equations, to second order implicit scheme has been applied for discretization of the governing equations. The $k$ - $\omega$-SST turbulence model has been used to estimate the eddy viscosity. Multiple reference frames have been used in this study. As a result, it is possible to divide the compressor hub into the stationary and rotating parts with respect 
to the inertial frame. The sliding interface has been used between the stationary and moving computational zones. Air velocity and its direction are fixed at the rotor inlet boundary in a stationary coordinate frame. For the outlet boundary, the static pressure distribution along the blade span is given by means of the well-known radial equilibrium law. No-slip and adiabatic wall conditions are imposed over all the solid walls. Adapted time step is considered so short for capturing the flow properties, precisely. In the unsteady simulation process, the time step is set in such a way that one blade passing to be completed in 120 steps. As a result, adopted sampling frequency is about $31 \mathrm{kHz}$ while blade passing frequency is $260 \mathrm{~Hz}$.

\section{Performance curves}

The tip clearance size of the rotor blade has been chosen as $2 \mathrm{~mm}$ for the current analyses, equivalent to that considered by Inoue et al. (1986) for their experimental works. So, it is possible to validate the present numerical results. This tip clearance size is equal to $1.7 \%$ of the blade tip chord length. Considering such a high tip clearance size can be helpful in a precise identification and a better physical interpretation of formation and development of the multiple spike stall cells.
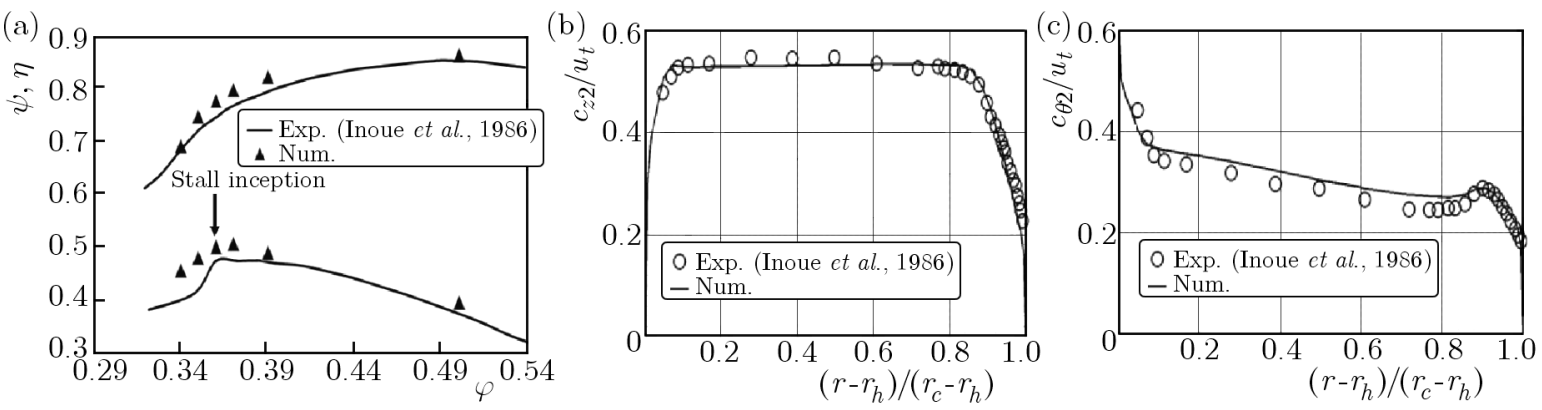

Fig. 2. (a) Compressor blade row performance curves. (b), (c) Normalized exit velocity distributions for design condition; (b) axial velocity, (c) tangential velocity; $c_{z}-$ axial velocity, $c_{\theta}-$ tangential velocity, $r, r_{c}, r_{h}-$ radius, casing radius and hub radius, $\psi$ - total pressure rise coefficient $\left(\Delta P /\left(0.5 \rho u_{t}^{2}\right)\right.$, $\eta$ - efficiency $(Q \Delta P / L), \Delta P$ - total pressure rise through the stage

The blade row performance curves, in terms of the stage loading factor and efficiency versus the flow coefficient, have been calculated, and the final results are shown in Fig. 2a. The experimental results of Inoue et al. (1986) are also superimposed in this figure which shows close agreement. Based on the present numerical results, the stall inception occurs at a flow coefficient of 0.36 . This point is highlighted in Fig. 2a. It is clear that the loading coefficient has slightly decreased at this flow coefficient.

Spanwise distributions of the exit axial and tangential velocity components, normalized with respect to the blade tip speed, are shown in Figs. $2 \mathrm{~b}$ and $2 \mathrm{c}$, respectively. The experimental data of Inoue et al. (1986) are also superimposed in these figures for comparison, which show close agreement. Circumferential averaged values of the flow field parameters are considered in plotting the curves presented in these figures.

\section{Stall cells}

Unsteady analyses have been performed at different mass flow rates near to stall conditions. The numerical simulations have been executed for about 11 rotor revolutions in order to detect the stall cells, their propagation and frequencies. Development and propagation of the stall cells 
(a)
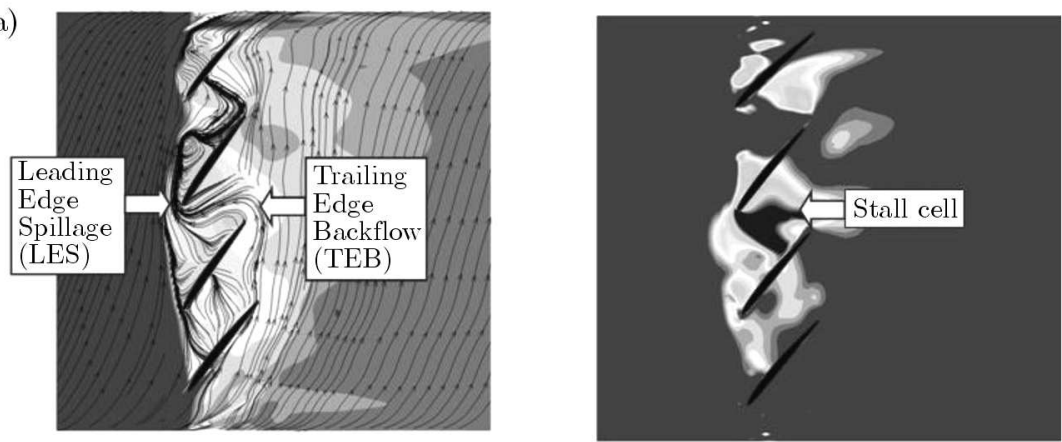

(b)
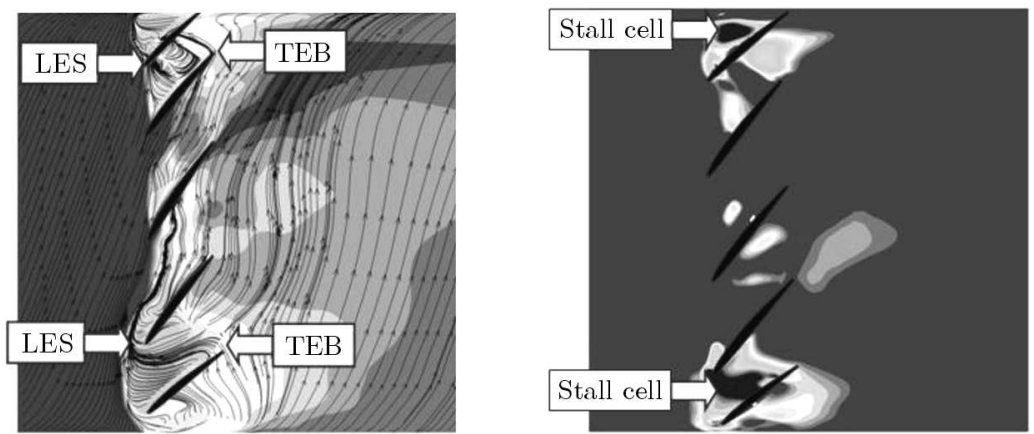

(c)
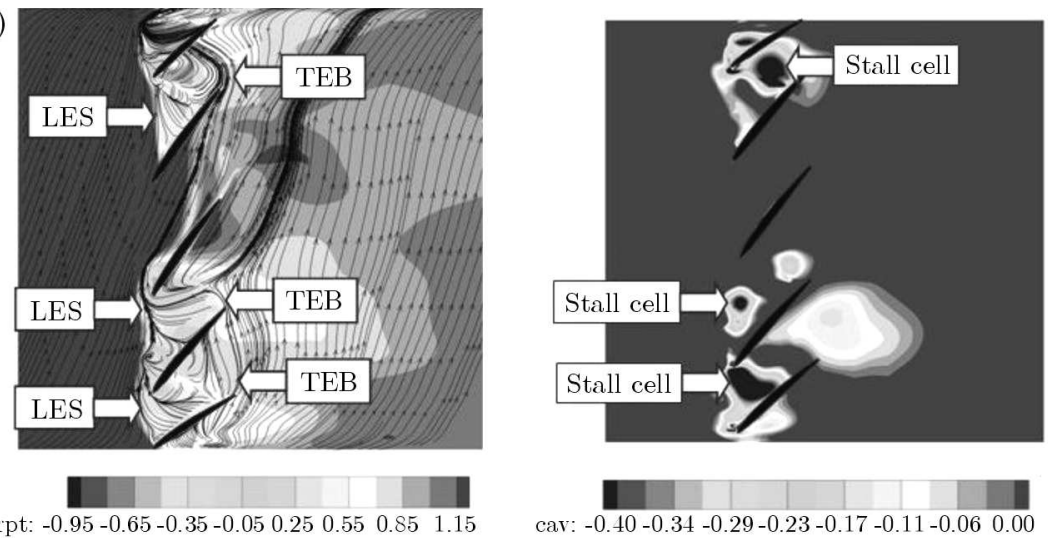

crpt: $-0.95-0.65-0.35-0.050 .250 .550 .85 \quad 1.15$

cav: $-0.40-0.34-0.29-0.23-0.17-0.11-0.060 .00$

Fig. 3. Flow fields in terms of time averaged relative total pressure contours (left figures) and axial velocity coefficient (right figures) at a $97 \%$ blade span; (a) spike stall inception, (b) 3 rotor revolutions after spike stall commencement, (c) 8.5 rotor revolutions after spike stall commencement

are shown in Fig. 3. These flow fields are shown for three cases of inception of spike stall and the subsequent 3 and 8 rotor revolutions. The left and right figures show the relative total pressure coefficient and the axial velocity contours, respectively. These results can be used for demonstration of the interface of the tip leakage flow and the main inflow. The streamlines patterns are also superimposed in the left side figures for a better recognition of the spike stall inception. Both the mechanisms of the trailing edge back flow (TEB) and leading edge spillage (LES), as the two main criteria for the spike stall formation, are highlighted in these figures. Negative axial velocities of the right figures reveal the low-energy and reversed flow regions. All results are presented on a plane located at $97 \%$ of the blades span.

Generally speaking, trajectory of the incoming/tip clearance flow interface results from a balance between the momentums of the incoming flow and the tip leakage flow. The spike stall occurs at the near stall condition, the position where can be reached through the throttling process of the main flow. As the incoming mass flow rate reduces, the axial momentum of the incoming flow decreases. On the other hand, the momentum of the tip leakage flow increases due to the increment of the blade loading. 
Flow fields of the spike stall inception, which has occurred at a specific flow rate $(\varphi=0.36)$, are demonstrated in Fig. 3a. As can be observed in this figure, in the case of spike stall occurrence (which has occurred at about 2.5 rotor revolutions), the trajectory of the incoming/tip clearance flow interface is completely detached from the blades leading edges, and a forward spillage of the tip clearance flow has occurred. In addition, the streamlines show reversed flow at the trailing edge plane. Therefore, two features of the flow which are responsible for stall inception (i.e., leading edge spillage and trailing edge backflow) have been formed. Finally, it can be understood that the spike stall has occurred under the proposed flow conditions (see Fig. 3a).

As can be observed in Fig. 3b, two aforementioned criteria for the spike stall commencement have occurred in two regions after three rotor revolutions (following the moment of the spike stall commencement). Each region is occupied by about two passages in the circumferential direction. The number of regions occupied by spike stall cells has increased to three at the instance of eight rotor revolutions after the spike stall inception (see Fig. 3c).

Referring to Fig. 3, it can clearly be recognized that in the regions where the spike stall has occurred the flow has reversed and caused considerable blockage to the main stream. As can be observed in this figure, the blockage size is not the same in all the passages. By passing time, the size of the stall cells do not increase significantly in the axial direction, but their number tends to increase.

Results of normalized flow angles with respect to the main inflow angle are shown in Fig. 4 for a $97 \%$ span plane. High incidence and reversal regions can easily be detected from this figure. These latter results are consistent with those obtained by Hoying et al. (1999).

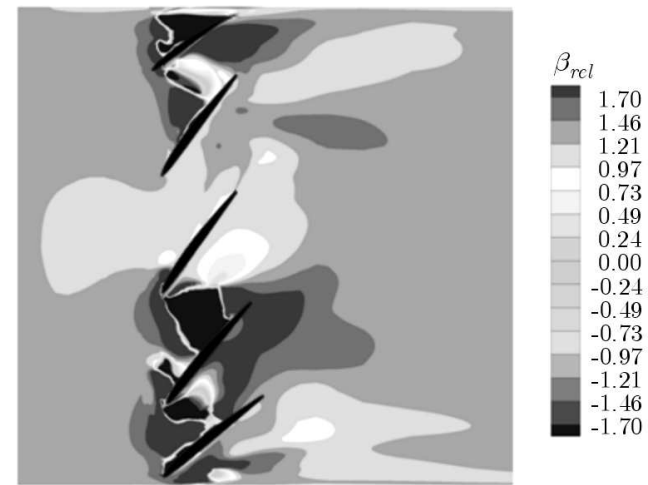

Fig. 4. Normalized flow angles at a 97\% span

It has been recognized that the radial distribution of the axial velocity along the blade span is an important parameter for the stall inception mode in axial compressors (Spakovszky et al., 1999). To find out the propagation characteristics of the stall cells in the radial and circumferential directions, the contours of negative axial velocities at a $50 \%$ axial chord cross plane are shown in Fig. 5. The results are illustrated in different times measured from the spike stall inception instant up to time of 8.5 rotor revolutions. It can be deduced that one stall cell occupies about $25 \%$ of the blades span at the stall commencement situation (see Fig. 5a). Similar to Fig. 3, by further rotation of the rotor, the number of stall cells increases without changes in their sizes. At $N=3$ and 8.5, two and three dominant stall cells have appeared, respectively (see Fig. 5c and Fig. 5f). Blocked regions have formed a thin band of small stall cells near the casing.

Based on the results presented in Fig. 5, it can be deduced that the stall cells rotate with a speed lower than the rotor blades in the relative frame system and in its opposite direction. This is the well known rotating stall phenomenon. 
(a) Spike inception
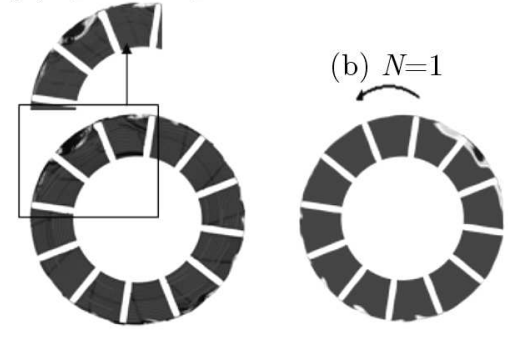

(c) $N=3$

(d) $N=5$

(e) $N=8$
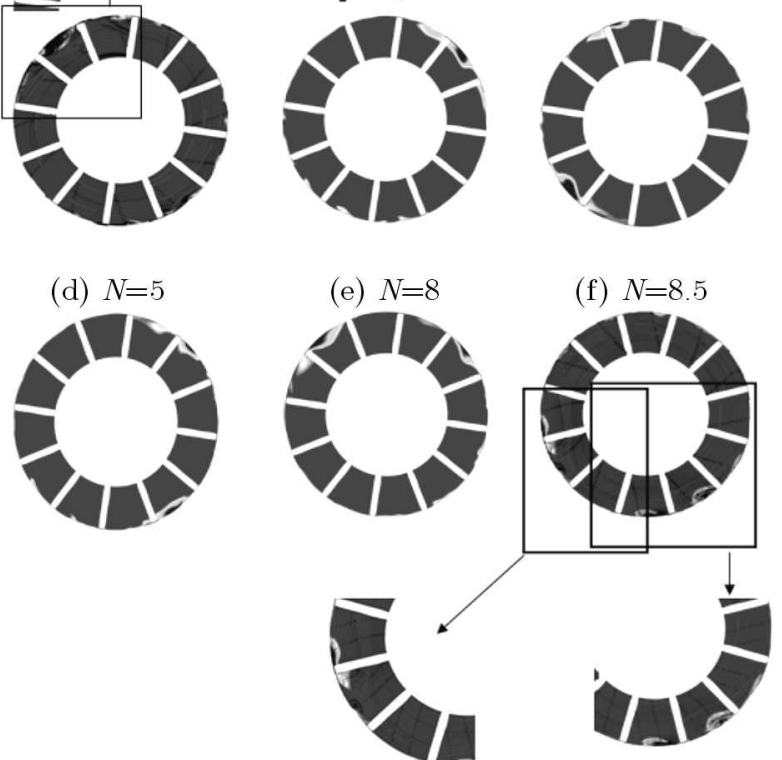

cav: $-\begin{array}{llllllll}0.40 & -0.34 & -0.29 & -0.23 & -0.17 & -0.11 & -0.06 & 0.00\end{array}$

Fig. 5. Time-averaged axial velocity coefficient at a $50 \%$ blade chord plane

\section{Frequency analysis}

To get a deeper insight into the flow characteristics during the stalling process, FFT (Fast Furrier Transformation) of the fluctuating flow has been executed. In this respect, a number of pseudo monitoring points have been distributed on the casing and the blade pressure side at a $97 \%$ blades span. These points are distributed evenly spaced within 10 to $90 \%$ of the blade chord length measured from its leading edge along the main stream direction. The points on the wall casing (designated by $\mathrm{C} 1$ to $\mathrm{C} 7$ ) are called fixed monitoring points, while those of the blades (designated $\mathrm{P} 1$ to $\mathrm{P} 7$ ) are called rotating monitoring points. The measuring points of $\mathrm{C} 1$ to $\mathrm{C} 7$ and $\mathrm{P} 1$ to $\mathrm{P} 7$ are introduced in Fig. 6. The sampling process of the numerical pressure signals has been started after the final convergence of the numerical solution. The raw signals of the static pressures and frequency spectrum results are shown in Fig. 7. These results are in terms of the PSD (Power Spectral Density) of the instantaneous pressure versus the flow frequency normalized with respect to the blade passing frequency $(\mathrm{BPF})$.

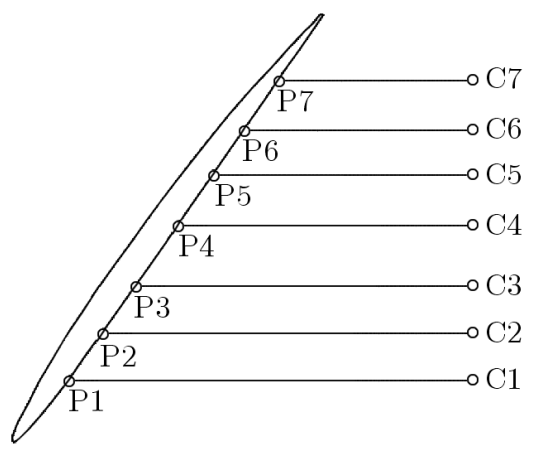

Fig. 6. Position of the monitoring points in the rotor tip region; $\mathrm{P}-$ on the blade surface, $\mathrm{C}$ - on the casing wall 
(a)

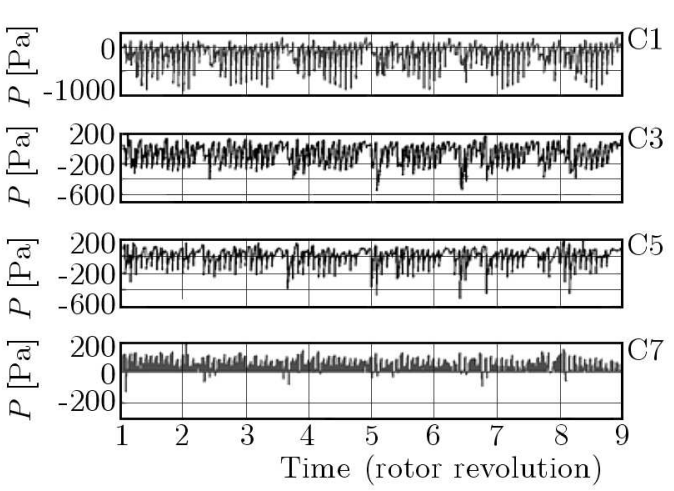

(b)

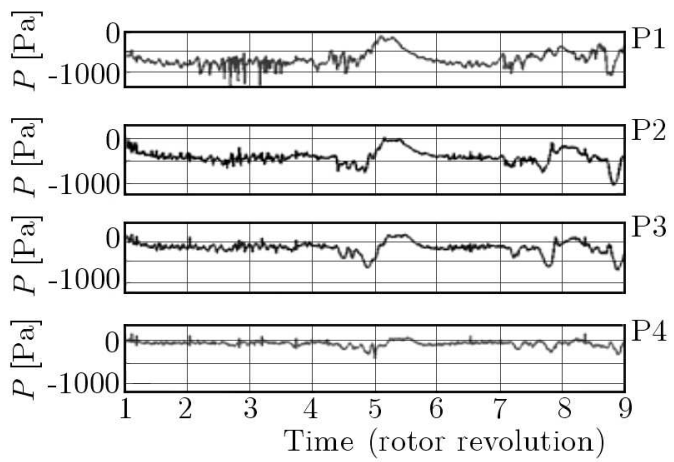

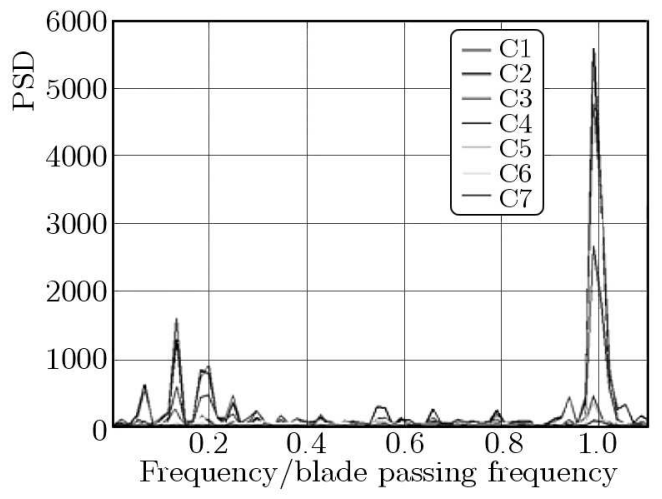

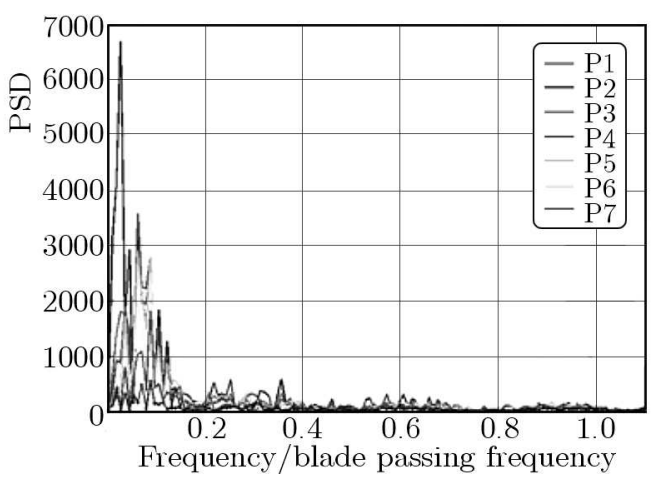

Fig. 7. Raw signals of instantaneous surface static pressures and their frequency spectrums in the rotor blade row tip region; (a) fixed monitoring points, (b) rotating monitoring points

(a)

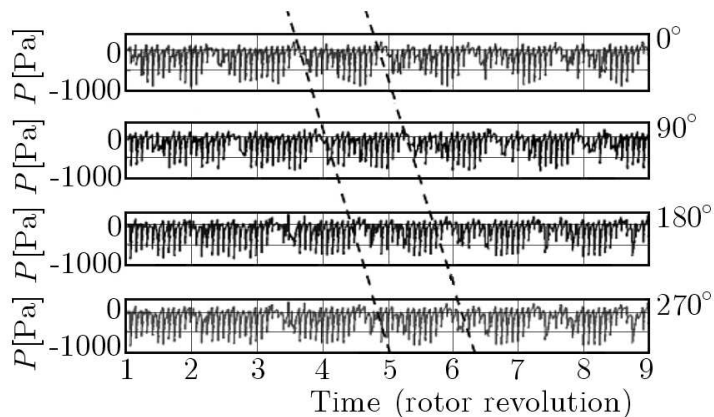

(b)

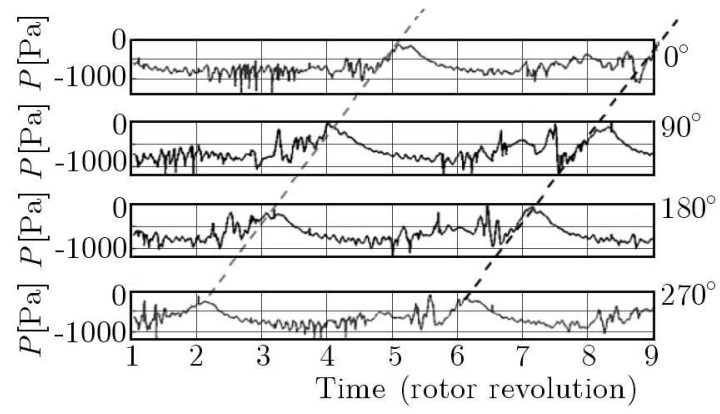

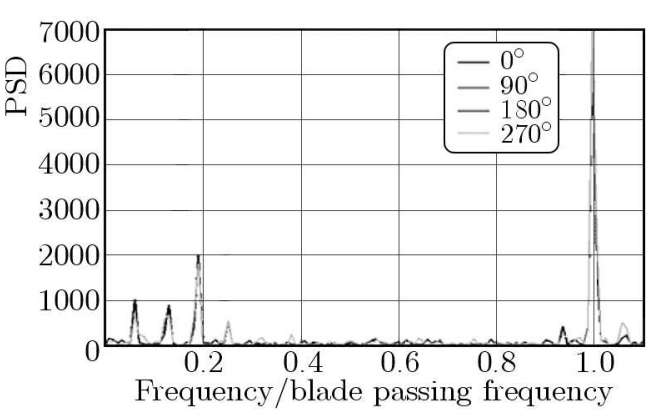

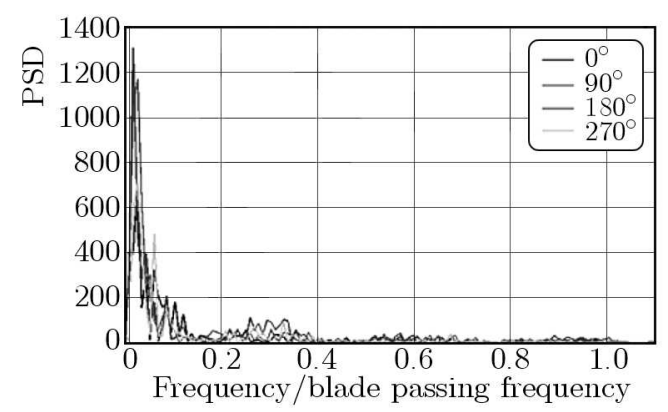

Fig. 8. Raw signals of instantaneous surface static pressures and their frequency spectrum at $10 \%$ chord of each blade; (a) fixed monitoring points, (b) rotating monitoring points

It can be deduced from Fig. 7a that the dominant frequency for the fixed monitoring points is less than 0.2 BPF. Obviously, BPF does not appear in the FFT results while dealing with the rotating monitoring points (see Fig. 7b). In the latter case, the dominant frequency is about $0.1 \mathrm{BPF}$. Several peaks of considerable magnitudes can be observed at each chordwise position, 
indicating the existence of the stall cells. This conclusion is in good agreement with the results of Vo et al. (2008), Zhang et al. (2005). They have shown that the periodic characteristics of the tip leakage flow can be recognized by occurrence of some peaks in the frequency spectrum at the near-stall condition. In addition, it is clear that the maximum amplitude of the pressure signals has occurred at $\mathrm{C} 1$ (or P1) at a position near to the blade leading edge. This is due to the existence of the tip leakage vortex flow in this region.

Frequency spectrum results at monitoring points set on $10 \%$ chord at different circumferential angles are shown in Fig. 8. The same frequencies and amplitudes of the unsteady flow can be observed for these monitoring points. However, a slight shift in the pressure signals can be observed with time when moving from one monitoring point to the adjacent one.

(a)

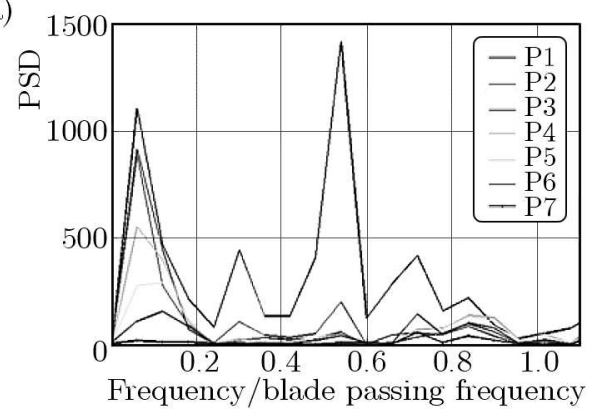

(b)

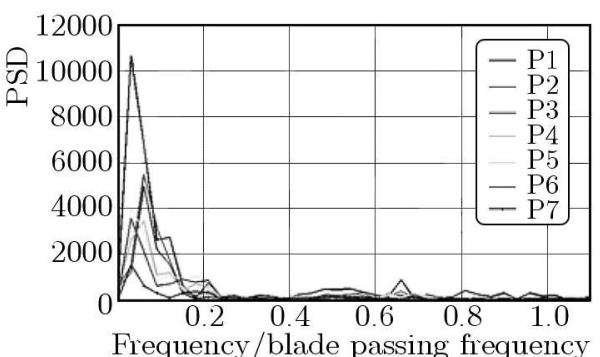

(c)

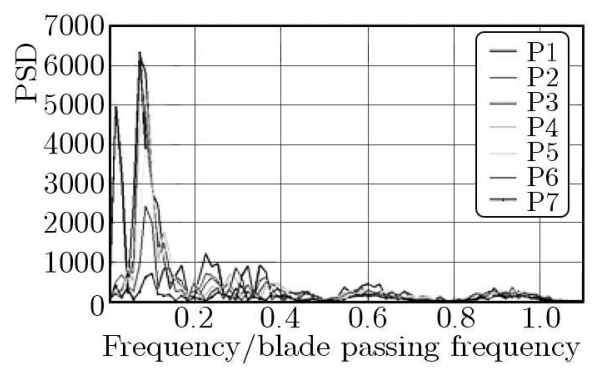

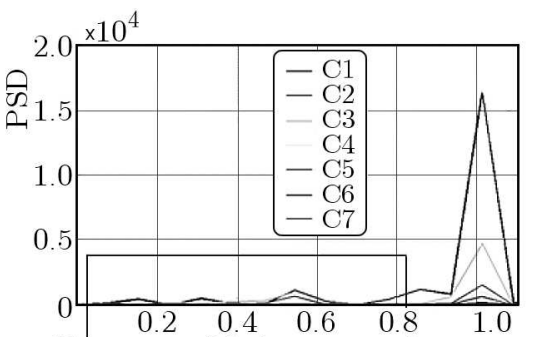

Frequency/blade passing frequency
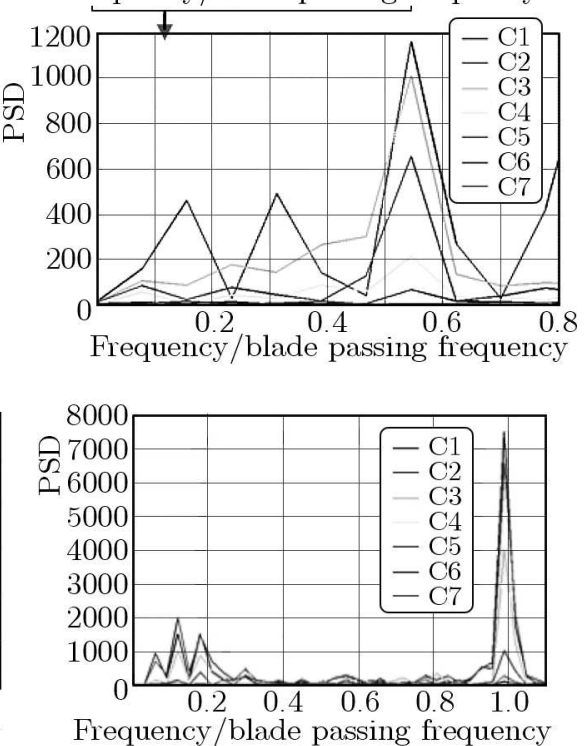

Frequency/blade passing frequency

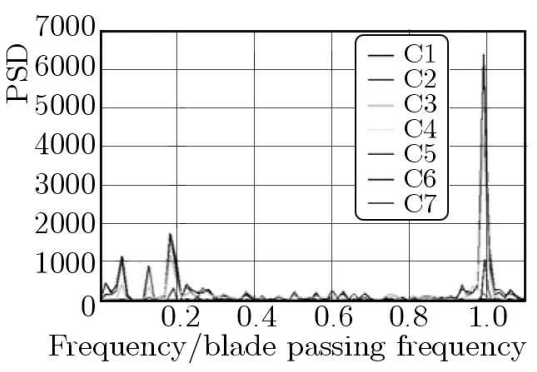

Fig. 9. Frequency spectrums at monitoring points; left column - rotating monitoring points, right column: fixed monitoring points, (a) 0-2.5 rotor revolution, (b) 2.5-5.5 rotor revolution,

(c) 5.5-11 rotor revolution

Generally speaking, the frequency survey over a long period cannot predict that every dominant frequency occurs within the specified time interval. As a result, the study should be carried out for a shorter time interval. Therefore, analyses have been performed at three time 
intervals of $N^{\prime}=0-2.5, N^{\prime}=2.5-5.5$ and $N^{\prime}=5.5-11$. These results are shown in Fig. 9 for both the fixed and rotating monitoring points. As can be depicted in this figure, the dominant frequency before $N^{\prime}=2.5$ at a fixed monitoring point is about 0.6 BPF. Within $N^{\prime}=2.5-5.5$, the dominant frequency changes to about 0.15 BPF. In this case, the difference between the amplitudes of the tip leakage flow and BPF is reduced. Similar results have been repeated for $N^{\prime}=5.5-11$.

Based on the results presented in Figs. 5 and 9, it can be concluded that the number of stall cells and flow blockages increase in time. The occurrence and continuation of spike stall cells cause the compressor to be faced into the fully developed rotating stall. This event is accompanied by flow unsteadiness with lower frequencies and higher amplitudes.

\section{Conclusions}

In this research work, a numerical study is carried out to analyze the development process of rotating stalls in a subsonic axial compressor. The main conclusions drawn from this research work can be stated as follows.

- Stall inception is linked to the tip leakage flow structure. Leading edge spillage and trailing edge backflow are main criteria for spike stall formation. This type of stall cell covers roughly two blade passages in the circumferential direction and about a $25 \%$ span in the radial direction.

- By passing time, the stall cells sizes remain nearly unchanged, whilst their number increases. For the present case study at 3 and 8 rotor revolutions after the commencement of the spike stall, two and three stall cells appear, respectively.

- In the relative frame set on the rotor blades row, the stall cells rotate in the opposite direction with a lower speed which is called rotating stall.

- Stall cells inception due to tip leakage vortices causes not only large blockage to main flow but also magnifies flow unsteadiness within the rotor blade passages.

- FFT of instantaneous static pressure signals showed that the tip leakage vortex frequency may reach 0.6 BPF just before the occurrence of spike stall, and then, by further revolution of the rotor blade row reduces to about 0.15 BPF.

- Spike stall may be eventuated to multiple stall cells which may be led to fully developed rotating stall. Consequent reversal flow may occupy most area of the flow passage while letting the rotor blades row to operate longer.

\section{References}

1. DAY I.J., 1993, Stall inception in axial flow compressors, ASME Journal of Turbomachinery, 115, 1-9

2. Deppe A., SaAthoff H., Stark U., 2008, Discussion: Criteria for spike initiated rotating stall, (Vo H.D., Tan C.S., Greitzer E.M., ASME Journal of Turbomachinery, 130, 011023)

3. Furukawa M., Inoue M., Saiki K., Yamada K., 1999, The role of tip leakage vortex breakdown in compressor rotor aerodynamics, ASME Journal of Turbomachinery, 121, 469-480

4. Furukawa M., Saiki K., Yamada K., Inoue M., 2000, Unsteady flow behavior due to breakdown of tip leakage vortex in an axial compressor rotor at near-stall condition, ASME Paper No. 2000-GT-666

5. Garnier V.H., Epstein A.H., Greitzer E.M., 1991, Rotating waves as a stall inception indication in axial compressors, ASME Journal of Turbomachinery, 113, 290-301 
6. Hah C., Bergner J., Schiffer H., 2006, Short length-scale rotating stall inception in a transonic axial compressorcriteria and mechanisms, ASME Paper No. GT2006-90045

7. НАн C., Rabe D.C., WAdiA A.R., 2004, Role of tip-leakage vortices and passage shock in stall inception in a swept transonic compressor rotor, ASME Paper No. GT2004-53867

8. Hoying D.A., TAn C.S., Vo H.D., 1999, Role of blade passage flow structures in axial compressor rotating stall inception, ASME Journal of Turbomachinery, 121, 735-742

9. Inoue M., Kuroumaru M., Fukuhara M., 1986, Behavior of tip leakage flow behind an axial compressor rotor, ASME of Engineering for Gas Turbine and Power, 108, 7-14

10. Mailach R., Lehmann I., Vogeler K., 2001, Rotating instabilities in an axial compressor originating from the fluctuating blade tip vortex, ASME Journal of Turbomachinery, 123, 453-463

11. Marz J., Hah C., Neise W., 2001, An experimental and numerical investigation into the mechanisms of rotating instability, ASME Paper No. GT-0536

12. Moore F.K., Greitzer E.M.A., 1986, Theory of post-stall transients in axial compression systems, Part I -Development of equations. Part II - Applications, Journal of Engineering for Gas Turbines and Power, 108, 231-239

13. Spakovszky Z., 2001, Application of Axial and Radial Compressor Dynamic System Modeling, PhD Thesis, Massachusetts Institute of Technology, U.S.A.

14. Spakovszky Z.S., Weigl H.J., Paduano J.D., Van Schalkwyk C.M., Suder K.L., BriGHT M.M., 1999, Rotating stall control in a high-speed stage with inlet distortion, part i: radial distortion, ASME Journal of Turbomachinery, 121, 510-516

15. Tryfonidids M., Etchevers O., Paduano J., Epstein A., Hendricks G.J., 1995, Prestall behavior of several high-speed compressors, Journal of of Turbomachinery, 117, 62-80

16. Vo H.D., TAn C.H., Greitzer E.M., 2008, Criteria for spike initiated rotating stall, ASME Journal of Turbomachinery, 130, 011023

17. Zhang H., Deng X., Chen J., et Al., 2005, Unsteady tip clearance flow in an isolated axial compressor rotor, Journal of Thermal Science, 114, 211-219 